\title{
PFIs Involving Multiple Public Partners: A Case Study from the Italian Health Care Sector
}

\section{Introduction}

Even if criticized at the academic and political level (Shaoul, 2005; HM Treasury, 2012), Private Finance Initiatives (PFIs hereafter) seem to have regained popularity during the last few years, (EPEC, 2016: 1). Because of the public financial crises and the coherence with the rhetoric of the NPM (Lapsley, 2009), PFIs, as a typology of Public Private Partnership (henceforth PPP), have been widely used for financing the provision of public infrastructures and related goods and services. However, many issues remain to be investigated in order to improve these initiatives (Andon, 2012).

Many scholars studied PFIs by mainly focusing upon the macro-level aspects and the calculations relating to PFIs (Cuthbert and Cuthbert, 2012; Shaoul, 2003, 2005; Edwards and Shaoul, 2003). Less interest has been devoted to the meso and micro-levels aspects, the long-term performance and the effects on the public sector of these initiatives (Andon, 2012; Broadbent et al., 2003).

PPPs are cooperation agreements of an enduring nature between public and private actors, through which they develop mutual products and/or services by sharing risks, costs and benefits (Klijn and Teisman, 2003). PPPs are defined as relationships between two types of subjects, one public and one private. Even if with potentially conflicting interests, mainly relating to the sharing of risks, these subjects are required to jointly provide public services for a long period. The focus on the nature of these subjects has led scholars to consider the interactions that constitute PFIs as an agency relationship between two actors only, where the main issue is to identify the reasons for participating in a PFI, and the conditions for defining the most sustainable deal (Klijn and Koppenjan, 2016; Shaoul, 2005). As the relationship arising from a PFI should last for a long period, calculations have been considered as the best tool for rationalizing future prospects and reducing the relative uncertainty (Carruthers et al., 1991), and therefore for legitimizing the public procurement decision for accountability purposes and for potentially governing any future event.

Recently, scholars are increasingly focusing their research on the non-technical aspects, and the contractual relational aspects of PFIs (Andon, 2012; Torchia et al., 2015). A better understanding of these aspects should streamline both the process of defining PFIs and their implementation. The involvement of many actors in PFIs has been recognized in the literature, and the role and influence of regulatory bodies has been particularly stressed (Burke and Demirag, 2017). The objective of this paper is to contribute to the PFI literature by providing a better understanding of the relationships among the actors involved in PFIs. In particular, it aims to overcome the public/private dichotomy underling the existing literature. Through the analysis of a critical case study (Yin, 1989), this paper analyses the relationships existing among various public actors participating in a PFI in the health care sector during its construction phase. The analysis mainly focuses upon the relationships between four health care trusts participating in a joint PFI for the construction of their hospitals, and between these actors and their regulatory body. The analysis of this case is interesting due to the potential benefits arising from the involvement of multiple contracting parties within a single PFI. These benefits are related with, savings that can be obtained because of the greater bargaining power of the public actors as a whole with respect to private actors, the economies of scale achieved during the partnership's definition phase, and the greater coordination of public investments. Like other papers (Grubnic and Hodges, 2003; Broadbent et al., 2003; English and Baxter, 2010), the analysis has been carried out using as a theoretical framework the concept of trust. This perspective is considered important in order to better understand, even with more formal tools (i.e. contracts), the development of the relationships among the actors involved in long-term relations (Sako, 1992) 
and thus contributing to the arrangement of a good governance system in a PFI (Torchia et al., in press).

The remainder of the paper is as follows. Section 2 establishes the theoretical framework and defines the specific issues under investigation, section 3 presents the case study, and the final section provides a discussion of the case and some final remarks.

\section{PFIs, public actors and trust}

PFIs have been long discussed from different points of view. Various roles have been attributed to the PFI - from that of a reform management tool, to that of a risk sharing tool - and numerous reasons have been attributed to its development - from public financial crisis to greater private efficiency (Andon, 2012; Torchia et al., 2015). Despite this widely-varied analysis, the lengthy duration of the relationship involved in a PFI, the inability to predict future events and the resulting consequences have led scholars to mainly focus upon two key issues: understanding both the costs and benefits arising from PFIs, and the allocation of the risks between the partners. This implies that a macro perspective has been preferred to a meso and a micro perspective, in order to better understand and analyze the conditions and modalities influencing the negotiations between the private and public actors involved in the partnership: PFIs have been seen more as a governance scheme than as a managerial tool (Teisman and Klijn, 2002).

Scholars have recently begun analysing PFIs on a more meso and micro levels. In particular, they are becoming increasingly aware of the need to recognise and adopt a multi-agency perspective in analysing PFIs in order to better understand their performance during both the procurement and implementation phases. This means unravelling the PFIs in order to consider the behaviour and perception of the various subjects throughout the entire lifespan of the partnership. In order to fully understand and govern PFIs, it is necessary to consider these initiatives from various perspectives: at the meso level the partnership between the public and private actors as a whole and, at the micro level the interactions between the public actors, the interactions between the private actors and the interactions among people operating within the same or different organisations.

To summarise (see Figure 1), PFIs can be studied at three different levels: macro, meso and micro. The former relates mainly to governance issues aiming at understanding the role of and the relationships between public and private sectors in providing public services. At the meso level, focus moves on issues and conditions for making convenient and successful the interaction among public and private organisations participating in a PFI. At the micro level, the interactions among organisations operating in the same sector (private or public) and the interactions among people operating in the different organisations involved in a PFI come to the surface.

\section{Insert Figure 1 about here}

While private actors collaborate through the settlement of the SPV, public actors operating at the same governmental level could collaborate in the definition and implementation of joint PFIs for a more efficient and effective provision of the infrastructures and services they are responsible for. Therefore, it might be helpful to understand the existing horizontal relations between the various public entities participating in the PFIs in order to better design these initiatives. Like in the private sector, partnerships among public actors can be affected by the level of competition, dependence and trust between the various partners involved (Scharpf, 1994; Sako, 1992). Trust could allow for a much more effective and efficient settlement of any potential conflicts that may arise within a partnership between the actors involved, whether at the same or different levels of an institutional system. According to Rousseau et al. (1998: 393) "trust may be a 'meso' concept, integrating microlevel psychological processes and group dynamics with macrolevel institutional arrangements".

Broadbent et al. (2003) classified trust in PFI in four categories: 
- $\quad$ system (the existence of institutional structures and/or standards of behaviour that enable the development of partnerships between public and private organizations),

- contractual (the assumption that the partner will fulfil the obligations in the contract),

- competence (the partners have the ability to carry out the activities established by the partnership),

- goodwill (if necessary, the partners will go beyond the contractual provisions in order to fulfil the expectations of the partner and achieve the objective of the agreement).

All these types of trust are jointly in action, and mutually support each other's enhancement within the PFIs. For example, system trust can facilitate the formation of contractual trust, given that a good institutional apparatus stimulates the contractual parties to respect and fulfil the obligations. Furthermore, the fulfilment of the contract can increase the goodwill trust since the former contributes to improve the quality of the relationships among the partners involved in a PFI.

The effects of the aforementioned types of trust on the PFIs' settlement and development depend on the characteristics of the partners involved in the PFIs. Each of them could perceive the risks associated with the PFIs differently, and consequently accept a different level of vulnerability in front of the other partners. Therefore, the public sector organisations' characteristics - bureaucracy, values, accountability (Rainey and Bozeman, 2000) - could affect the trust relationships between the public actors involved in PFIs.

Because of the higher level of formalization and red tape in public sector organizations compared to private sector ones, system trust and contractual trust are a very important governance tool, especially during the ex ante phase of the PFIs. The existence of an institutional structure and/or the definition of a well-structured and comprehensive contract are the best ways to manage public managers' political or economic responsibilities. This is especially true when public actors are accountable at the same superior governmental level or (in)directly compete for the allocation of resources. The reasons underlying the beginning of a partnership could affect the role played by the different typologies of trust. If the PF is a voluntary initiative, public partners could be less interested in the detailed definition of the agreement from the outset because of their prevalent interest in initiating a partnership with the other public actors. Conversely, if a superior administrative body has decided the participation in the PFI, the public actors could be much more interested in defining their responsibilities in the contract, especially of a financial nature. "The protectionist system of budgetary categories is one of the most severe limits on the possible scope of interagency collaboration" (Bardach, 1998: 122).

The role played by the regulatory body may affect the relations between the partners. If the PFI were to be imposed on the public actors by the regulatory body, public contractors might put more trust in the system. The role played by the regulator could increase the trust among the various public actors if any issues should arise and the regulator will be more inclined to intervene in order to resolve disputes within the partnership. Burke and Demirag (2017) have analysed how the relationships between the Procuring Authority and the other stakeholders could affect the allocation of risk within PFIs. The Procuring Authority played a supporting and proactive role in risk sharing with both the public and private sector stakeholders. This behaviour was mainly justified by the goal of increasing goodwill in the future and ensuring the project's fundability by the senior debt financiers. A proactive and supporting type of behaviour has also been highlighted between public sector stakeholders, even if they could have contrasting objectives. A positive perception of the efficiency and experience of the Procuring Authority in allocating risks helped to decrease the potential for contrasting relationships. In PFIs involving multiple public administrations operating at the same governmental level competence might be reason for competition. In PFIs, the expertise and efficiency of private subjects have always been two of the fundamental reasons to create partnerships for the construction of infrastructures and for the management of certain phases of the public service procurement process. Where the relationship occurs between similar subjects (i.e. public actors), competence could be an obstacle to the development of the relationship, because, in 
a competitive manner, each of the actors involved in the partnership shall seek to bring the most relevant competence possessed with respect to those of the other actors. This obstacle could also arise due to the call for differentiation stemming from the public sector reform processes, the socalled pluralism problem (Bardach, 1998), and the ultimate accountability of the public actors in relation to the citizens they represent. For many of the public services provided, the public administrations operate as a "professional bureaucracy" (Mintzberg, 1979). Professionals working within similar public organisations that are involved in a PFI could overestimate its competences with respect to those of others and this could give rise to contrasts in reaching certain agreements or collaboration throughout the lifespan of PFIs. Therefore, if referring to partnerships between public actors, competence trust has a little influence in the settlement of the contract at the beginning of the PFIs, or even in the resolution of any problems or conflicts that may arise during the implementation of the PFIs. Competence trust could play a different role if considered in the relationships between the contracting authorities and the regulator. For an effective and efficient provision of public services, the regulator could allocate functions among the various participants based on the level of competence trust placed in the various public actors involved in the PFI. Mainly in the sectors where public administrations compete for obtaining financing, the regulatory body has to avoid that competition could produce financial irrationality due to the proliferation of providers of similar services and/or generate poor quality resulting from the action of providers not adequately competent.

In partnerships, reliance on goodwill trust should be higher between public actors than what might happen in relationships between subjects belonging to different sectors. This belief stems from the existence of a system-wide commonality of values and objectives in the public sector, in many cases stated at the institutional level. The lengthy duration of PFIs and the achievement of a common final and superior objective (e.g. public health) could induce public partners to believe that any compromise reached, even in contrast to their own interests, within a certain time frame, will be balanced in later developments. Therefore, both during the ex ante phase and the implementation of the PFIs, public actors could more easily define a(n) (new) agreement to meet unexpected circumstances in the expectation of equal and similar treatment by their counterparts. The presence of scarce system trust, i.e. the presence of a regulatory body not fully involved in PFIs, makes a higher level of goodwill trust necessary among public actors in order to render the partnership much more effective. The regulatory body could help to enhance the level of goodwill trust among the public partners involved in a PFI by developing and implementing performance measurement systems and funding systems that are capable of fostering cooperation rather than competition among public actors.

On the basis of the literature on PFIs and trust and focusing on the relationships among public organisations involved in a PFI in the health care sector, this paper aims at analysing mainly two issues. First, which kinds of trust are mobilised among health care trusts for the development of a PFI and, second, which is the role of the regulatory body for the development of the relationships among health care trusts involved in a PFI.

\section{The empirical analysis}

The case study examined is currently the only example in Italy of a joint PFI procedure involving multiple public health care trusts as contracting parties. The contracting parties for the PFI are four health care trusts from the Tuscany region (Prato, Pistoia, Lucca and Massa-Carrara), which used this procedure to contract the construction of four new hospitals in 2007, and to manage nonmedical services for 19 years. The four local health care trusts did not act based on an independent decision, but rather based on the guidance of an overarching regulatory body, the Tuscany regional administration. The regulator believed that the joint PFI would have resulted in both more advantageous prices with respect to the tender limit price for the health care trusts and a more efficient health care system by programming health care services that would be complementary to 
one another. The Tuscany region has also requested the establishment of an inter-trust body for coordinating the activities relating to the PFI. For this reason, the association known as the "Sistema Integrato Ospedaliero Regionale (SIOR)" (Integrated Regional Hospital System) was established in 2003, with the task of managing the PFI along its whole life.

The total investment for building the 4 hospitals was approximately 421 million Euros, and the construction began in 2010 and ended between 2013 and 2014.

The case study was developed through the analysis of the available documents and by conducting, from 2015 to 2016, twenty semi-structured interviews with the top management of the public health care trusts involved in the PFI.

This section provides an analysis of the main findings concerning the relationships between the four public health care trusts from the time that the SIOR was established until all the hospital facilities were completed. As reflected in the following statements, it should be noted that, for PFIs involving multiple public subjects, the prompt identification of the future financial commitments assumed by each partner plays a fundamental role. To this end, the drawing up of the financial plan (hereafter FP) represents the main opportunity to delineate each public partner's specific responsibilities. The effort made to identify the responsibilities of the individual contracting parties is also motivated by the fact that the joint nature of the PFI did not constitute a free choice, but rather a specific directive of the regional administration. In a partnership decided by the regulatory body during the PPP's startup phase, trust between the public administrations involved in does not necessarily represent a resource upon which to base the collaboration. Therefore, the establishment of a well-built PFI contract could represent one of the prerequisites for a good start to the initiative.

\begin{abstract}
"The identification of each health care trust's financial contribution through the FP, with regard to both the financing of the new hospitals' construction, as well as the remuneration of the non-medical services, engaged the SIOR for a long period of time prior to the awarding of the contract. In fact, even if there is a joint FP, each of the public partners' expenditures were promptly identified in order to specify the commitments undertaken by the each one beforehand, and to take them into account in the medium and long term corporate planning documents" [General Manager of one of the health care trusts]
\end{abstract}

\begin{abstract}
"The fact that the project was of a joint nature never made us lose sight of the individual companies' perspectives, and the financial responsibilities assumed by each public partner. Even at the behest of the concessionaire, every possible effort was made to avoid the vagueness of liability that could have resulted from the presence of multiple contracting parties, as well as to prevent any possible disputes between them" [Administrative Director of one of the health care trusts]
\end{abstract}

However, the identification of the commitments to be assumed by each partner did not end with the definition of the FP, and they were subsequently reviewed during the rebalancing of the FP in the cases covered by the signed contract. The FP was revised three times from 2010 to 2014 due to variations in the projects requested by the contracting parties while the work was in progress, as well as due to delays in two of the four hospitals becoming operational, as a result of unexpectedly long commissioning times. The variations to the hospitals' initial projects did not give rise to any particular issues in the relationships between the public partners and between them and the concessionaire. This was possible because the calculation of the increase to each health care trust's contribution was closely linked to the financial value of the additional works commissioned by each of them. The greater volumes constructed also resulted in an increase in certain costs relating to the services entrusted with the PFI (e.g. cleaning and maintenance). The negotiations between the PFI's actors did not result in any particular tensions in this case either, since the FP's original structure allowed for each health care trust's management phase costs to be redetermined by increasing the quantity of the services to be acquired by each contracting party in proportion to the increase in the volumes constructed. 


\begin{abstract}
"The cost of the design variants and the higher service costs linked to the greater volumes constructed with respect to those originally foreseen were both charged to the individual health care trusts based on their new demands. The initial FP's structure was crucial for avoiding conflicts; having promptly indicated the costs attributable to each health care trusts beforehand allowed for the costs attributable to each public partner to be re-elaborated during the process of rebalancing the FP in a sufficiently objective manner, which was therefore accepted by the individual contracting parties" [Administrative Director of one of the health care trusts]
\end{abstract}

Different considerations must be made, on the other hand, with regard to the extension of the lead times for two of the four hospitals (10-month delay for the Massa-Carrara hospital and fourmonth delay for the Lucca hospital). These delays were caused by the Massa-Carrara and Lucca health care trusts rendering the construction land available to the concessionaire over a longer time frame with respect to that which was indicated in the initial project. The fact that two hospitals became operational late with respect to the time frames indicated in the original FP resulted in the need to rebalance the plan mainly for two reasons. The concessionaire's revenues arising from the management of the non-medical services were lower than those quoted in the FP. Consequently, the borrowing costs, relative to the mortgage stipulated by the concessionaire, were higher because the debt repayment period, which for PFI operations usually begins with the start of the management phase, began at the date upon which the last hospital became operational. After long and complex negotiations, which even required the involvement of financial and legal consultants, two agreements came up. The FP was rebalanced by extending the concessions for the services so that all would expire 19 years after the date upon which the last hospital became operational, and by the public contribution increased of an amount equal to the higher borrowing costs incurred by the concessionaire. The contracting parties agreed to divide this amount among themselves in proportion to the percentage of each hospital's construction costs with respect to the value of the overall investment. In this manner, the cost for rebalancing the FP was also paid by the trusts that had not caused an extension of the construction period.

\begin{abstract}
"The cost of the delays with which some of the facilities became operational were paid by all the health care trusts, even those which had not caused any delays. This also depended on the joint $F P$, which, with regard to the delayed implementation of the overall management phase, did not provide for any mechanism that would allow for the responsibilities and the relative charges attributable to the individual health care trusts to be determined after the delay, in the event that the construction deadline might be delayed for reasons not attributable to the private party" [General Manager of one of the health care trusts]
\end{abstract}

From interviews came to light the expectancy of the top management of the health care trusts of an authoritarian intervention of the regional administration to fix any arising problem in the PFI. Specifically, because of its directive to create a joint PFI, the regional administration was supposed to resolve any potential conflict related with the updating of the FP caused by the delays of some public partners in implementing the management phase of their hospitals. Although the regional administration did not intervene, the public partners were able to come up with a compromise on their own, which prevented the partnership from potentially collapsing. In other words, even though the hierarchy did not intervene, the partners' ability to dialogue and their willingness to come to an agreement allowed them to overcome this relational crisis, which was caused by an event not covered by the contract.

\footnotetext{
"While the SIOR, and its Chairman in particular, have always focused a great deal of attention upon respecting the time frames for building the hospitals, this association, which is made up of the General Managers of the four health care trusts involved in the PFI, is a Committee of equals in which no one, not even the Chairman, has any overriding power in the event that certain goals are not achieved. Since nobody has hierarchical powers within the SIOR, nobody
} 
is able to punish the non-achievement of the established goals. Sometimes the managers of the regional administration took part in the SIOR meetings, but without holding any formal roles within the SIOR itself' ' [General Manager of one of the health care trusts, and former Chairman of the SIOR]

\begin{abstract}
"The joint PFI should have included the identification of a subject who could intervene with authority in order to determine and implement the necessary corrective actions in the event of the failure to achieve the established goals. In our case, the regional government's failure to intervene in order to resolve a potential conflict among the health care trusts made necessary to find a compromise, otherwise the project initiative would have suffered a crisis harmful to everyone" [General Manager of one of the health care trusts]
\end{abstract}

In the case analysed, the goodwill trust, which is also linked to the relationships between public actors, was revealed a resource of fundamental importance for ensuring the continuity of the partnership and the achievement of its goals. As shown by the following statement, the propensity for dialogue and a willingness to pursue joint solutions both played a key role in helping the public partners overcome these controversies.

"When we needed to come to an agreement on how to divide the FP re-balancing costs resulting from the delay in certain hospitals becoming operational, the SIOR was able to offer almost ten years of experience and a consolidated ability to take on joint problems. All of these elements played a part in helping us reach an agreement" [General Manager of one of the health care trusts]

In conclusion, it should be noted that the empirical evidence gathered shows that one of the Tuscany region's goals that motivated the decision to make use of a joint PFI has still not been achieved. Each health care trust is providing its own services instead of working as being part a network of providers. The failure to achieve this goal was due to the Tuscany region's failure to intervene, as the regulatory body responsible for the planning of health care service, for the creation of the described network. The failure was also due to the in adequacy of the performance evaluation system and of the health care trusts financing mechanism to take into account the need to incentivize the creation of complementary health care service structures.

"No effort was made to promote the SIOR's integrated hospital network. In order to achieve this result, it would not have been sufficient to establish an ad hoc inter-agency work group consisting primarily of health care directors. In fact, network-style planning requires political coverage by the regional government, since the local political forces insist upon having the entire range of health care services available within their own territories, and do not seem to be aware of the possible effects that this type of attitude can have on performance in terms of efficiency and effectiveness" [General Manager of one of the health care trusts]

"While the idea of building a cooperative network of hospitals was certainly a valid one, innovations of this type must also be properly managed after being launched. Although I pressed for one, the regional administration was not given an active role to play. The regional government has the power to define the goals that the health care trusts and the individual general managers must achieve, as well as to establish the trust financing mechanisms. Neither the former nor the latter were used as tools to incentivize the creation of the cooperative network, which in fact guided the joint project financing decision for multiple agencies. [...] Consequently, the health care trusts were not even required to address the problem of how to make professionals work together from different health care facilities, many of which were not very inclined to operate within a network-type organization" [General Manager of one of the health care trusts and former Chairman of the SIOR] 


\section{Discussion and final remarks}

PFIs are complex partnerships whose success and whose effective and efficient management requires an understanding of the objectives and the consequent behaviour adopted by each partner. This is especially crucial in the design phase of PFIs, since every decision adopted during this phase will have effects on the future development of the initiative itself. The literature on PFIs, taking a more macro perspective, has been primarily concerned with understanding the reasons for the increased use of such forms of partnership, especially during the last decade, and identifying appropriate assessment methodologies (Andon, 2012). Only recently, the analysis has focused more upon the relationships between the various actors participating in the PFIs (Burke and Demirag, 2017; Petersen, 2011). Reasons related to economic evaluations or public policy planning issues could incentivize public actors to work together in order to design more complex PFIs comprising similar initiatives within a single contract. In such cases, it is essential to understand not only the relationships between the public and private actors, but also the relationships between the public actors involved in the PFI. The case study analysed in this paper can provide some knowledge to render the design of PFIs more effective and efficient, while at the same time engaging more public actors.

The establishment of a sound and sustainable partnership in PFIs involving multiple public agencies makes necessary the prior identification of the individual public partners' responsibilities and future expenses towards both the private partner and the other public partners. A PFI contract and a relative FP that effectively meet the needs in question can help to prevent relational crises between public and private subjects, as well as between the various public agencies involved in the PFI itself. This aspect is also particularly important because, during the PFI's execution, it may be necessary to review/update the initial contractual conditions (e.g. when the economic and financial plan needs to be rebalanced). The more these reviews/updates are addressed within the initial PFI contract, the easier it will be to reach these new agreements, above all during the initial phase of the partnership (when there is usually a lesser degree of trust between the partners). This comprehensive type of contract formulation is essential for public administrations, above all when you consider that any contractual variation in the PFI that has an effect on the FP will also have an impact on either the availability or the allocation of the public resources available, and could therefore also affect the relationships of these administrations with their stakeholders.

However, the comprehensive type of contract formulation described above cannot be expected to foresee all the possible situations that could arise during the PFI's execution and the relative rights/duties of the partners (Madhok, 1995). Therefore, in addition to respecting the contractual clauses, other mechanisms must also be utilized in order to overcome any potential conflicts and relational crises that may arise within the partnership. In this regard, it is important to develop trust in the institutional structure of the PFI and the results that it can help to achieve (system trust), as well as to develop trust between the partners (especially goodwill trust). In the types of PFIs referred to herein, the conflicts can arise within the relationships between public and private subjects, as well as between the public partners. In the case of PFIs involving multiple public subjects operating within a system governed by a regulatory body, the latter is expected to intervene in order to resolve any disputes that may arise between the public subjects. If the regulator should fail to intervene, the disputes may be resolved through the public partners' willingness to compromise (goodwill trust). This hypothesis is further supported by a long PFI duration. The partners might consider the balancing of their various positions to be acceptable over the long term, and therefore might be more willing to accept solutions that might not initially appear to be convenient if only considered from a short-term perspective. To this end it could be useful to develop and implement decision support systems able to focus actors' attention and interests on the long-term effects more than on the short-term ones. An important role in this perspective could be played by regulatory bodies. The increasing use of PFIs for providing public services "do not imply 'less government' but a different governmental role" (Torchia et al., 2015: 248; Pongsiri, 2002). 
It is necessary, however, for the public subjects to develop an ability to work in a collaborative manner, and therefore to embark on a pathway of establishing mutual trust, above all when the regulatory body refuses to intervene. In the relationship between the public subjects involved in the PFI, the case analysed shows that a weak system trust - understood as a lack of actions promoted at the institutional level by the regulatory bodies in order to sustain and protect the partnership and the individual actors involved in (Deakin et al., 1997; Broadbent et al., 2003) - can be compensated with a solid goodwill trust.

Nevertheless, goodwill trust is not capable of completely replacing system trust. In order to pursue an objective of specialization in the provision of services, a more active role of the regulatory body is necessary to take into account the complementary characteristics of the various health care trusts (Shaoul, 2005). The case study shows that, unlike that which occurred to overcome the relational crises between the PFI's actors, the goodwill trust of the various partners did not work towards the creation of a network of health care trusts. The achievement of this goal did not only require agreements to be reached on an inter trust level, but also required a local political consensus and/or regional "political coverage". In this regard, the action of the regulatory body would have been fundamental in terms of both planning the health care services and defining the mechanisms that incentivize collaboration among the public actors (Jamali, 2004; Scharle, 2002). Afterwards, the health care trusts would have been required to identify the most suitable strategies for convincing the professional to cooperate, even by designing inter-trust pathways. The development of the different typologies of trust among the public actors involved in a PFI can contribute to achieving higher level of good governance standards (Torchia et al., in press). In particular, higher levels of goodwill trust could make easier and faster the resolution of conflicts avoiding any delay in the progress of the PFI. Similarly, the development and use of higher level of competence trust could contribute to the improvement of health care services as each health care trust participates in a PFI according to its competences.

The paper has a number of limitations mainly related to problems of generalization. The analysis refers to one case study and focuses on the PFI construction phase. This implies the need to conduct additional case studies, and to expand the analysis of the relationships among multiple public actors to include the PFIs' execution phase as well. Another limit of the paper is the focus upon the health care sector. The specificities of this sector could impact upon the relationships between the public partners participating in PFIs, and the functioning of the trust mechanisms between these actors. 


\section{References}

Andon, P. (2012), Accounting-related research in PPPs/PFIs: present contributions and future opportunities. Accounting, Auditing \& Accountability Journal, 25, 5, pp. 876-924.

Bardach, E. (1998), Getting Agencies to Work Together. The Practice and theory of Managerial Craftsmanship, Washington: Brookings Institution Press.

Broadbent, J., Gill, J. and Laughlin R. (2003), The Development of Contracting in the Context of Infrastructure Investment in the UK: The Case of the Private Finance Initiative in the National Health Service. International Public Management Journal, 6, 2, pp. 173-198.

Burke, R. and Demirag, I. (2017), Risk transfer and stakeholder relationships in Public Private Partnerships. Accounting Forum, 41, 1, pp. 28-43.

Carruthers, Bruce G., Espeland and Wendy N. (1991), Accounting for Rationality: Double-Entry Bookkeeping and the Rhetoric of Economic Rationality. American Journal of Sociology, 97, 1, pp. 31-69.

Cuthbert, J.R. and Cuthbert, M. (2012), Why IRR is an inadequate indicator of costs and returns in relation to PFI schemes. Critical Perspectives on Accounting, 23, 6, pp. 420-433.

Deakin, S., Lane C. and Wilkinson F. (1997), Contract Law, Trust Relations and Incentives for Cooperation: A Comparative Study. In Deakin, S. and Michie, J. (eds), Contracts, Co-operation and Competition: Studies in Economics, Management and Law, Oxford University Press, Oxford.

Edwards, P. and Shaoul, J. (2003), Partnerships: for better, for worse? Accounting, Auditing \& Accountability Journal, 16, 3, pp. 397-421.

English, L. and Baxter, J. (2010), The Changing Nature of Contracting and Trust in Public-Private Partnerships: The Case of Victorian PPP Prisons. Abacus, 46, 3, pp. 289-319.

EPEC (2016), Market Update. Review of the European PPP Market, First half of 2016. http://www.eib.org/epec/resources/publications/epec_market_update_2016_h1_en

Grubnic, S. and Hodges, R. (2003), Information, Trust and the Private Finance Initiative in Social Housing. Public Money \& Management, 23, 3, pp. 177-184.

HM Treasury (2012), A new approach to public private partnerships, http://www.hmtreasury.gov.uk

Jamali, D. (2004). Success and Failure Mechanisms in Public Private Partnerships (PPPs) in Developing Countries. Insights from the Lebanese Context, International Journal of Public Sector Management, 17, 5, pp. 414-430.

Klijn, E.-H. and Teisman G. (2003), Institutional and Strategic Barriers to Public- Private Partnership: An Analysis of Dutch Cases. Public Money \& Management, 23, 3, pp. 137-145.

Klijn, E.H. and Koppenjan, J. (2016), The impact of contract characteristics on the performance of public-private partnerships (PPPs). Public Money \& Management, 36, 6, pp. 455-462

Lapsley, I. (2009), New Public Management: The Cruellest Invention of the Human Spirit? Abacus, 45,1, pp. $1-21$.

Madhok, A. (1995), Opportunism and trust in joint venture relationships. Scandinavian Journal of Management, 11, 1, pp. 57-74.

Mintzberg, H. (1979), The structuring of organizations, Englewood Cliffs: Prentice-Hall.

Petersen, O. H. (2011). Multi-level governance of public-private partnerships: An analysis of the Irish case. Halduskultuur-Administrative Culture, 12, 2, pp. 162-188.

Pongsiri, N. (2002). Regulation and Public Private Partnerships, The International Journal of Public Sector Management, 15, 6, pp. 487-495.

Rainey, H. G., and Bozeman, B. (2000), Comparing public and private organizations: Empirical research and the power of the a priori. Journal of public administration research and theory, 10, 2, pp. 447-470.

Rousseau, D.M., Sitkin, S.M., Burt, R.S. and Camerer, C. (1998), Not So Different After All: A Cross-Discipline View of Trust. Academy of Management Review, 23, 3, pp. 393-404. 
Sako, M. (1992), Prices, Quality and Trust: Interfirm Relations in Britain and Japan, Cambridge University Press, Cambridge.

Scharle, P. (2002),. Public-Private Partnership (PPP) as a Social Game. Innovation. The European Journal of Social Sciences, 15, 3, pp. 227-252.

Scharpf, F. (1994), Games Real Actor Could Play. Journal of Theoretical Politics, 6, 1, pp. 27-53.

Shaoul, J. (2003), A financial analysis of the National Air Traffic Services' PPP. Public Money \& Management, 23, 3, pp. 185-194.

Shaoul, J. (2005), A critical financial analysis of the Private Finance Initiative: selecting a financing method or allocating economic wealth. Critical Perspectives on Accounting, 16, 4, pp. 441-471.

Teisman, G.R. and Klijn, E.H. (2002), Partnership Arrangements: Governmental Rhetoric or Governance Scheme? Public Administration, 62, 2, pp. 197-205.

Torchia, M. and Calabrò, A. (in press), Increasing the Governance Standards of Public-Private Partenerships in Healthcare. Evidence from Italy. Public Organization Review, DOI: 10.1007/s11115-016-0363-1.

Torchia, M., Calabrò, A. and Morner, M. (2015), Public-Private Partnerships in the Health Care Sector: A systematic review of the literature. Public Management Review, 17, 2, pp. 236-261.

Yin, R. K. (1989). Case study research: Design and methods. Newbury Park: Sage Publications. 